\title{
Reduced bone mineral density in men after heart transplantation
}

J.R. Anijar ${ }^{1}$, V.L. Szejnfeld ${ }^{1}$, D.R. Almeida², A.R. Fernandes ${ }^{3}$ and M.B. Ferraz ${ }^{1}$

\author{
Disciplinas de ${ }^{1}$ Reumatologia, ${ }^{2}$ Cardiologia and ${ }^{3}$ Radiologia, \\ Escola Paulista de Medicina, Universidade Federal de São Paulo, \\ São Paulo, SP, Brasil
}

\begin{abstract}
\section{Correspondence}

J.R. Anijar

Disciplina de Reumatologia

Universidade Federal de São Paulo

Rua Botucatu, 740

04023-900 São Paulo, SP

Brasil

Fax: + 55-11-576-4239

E-mail: jdb@ mandic.com.br

Publication supported by FAPESP.

Received April 7, 1998

Accepted December 21, 1998

Heart transplantation is associated with rapid bone loss and an increased prevalence and incidence of fractures. The aim of the present study was to compare the bone mineral density (BMD) of 30 heart transplant (HT) recipients to that of 31 chronic heart failure (CHF) patients waiting for transplantation and to determine their biochemical markers of bone resorption and hormone levels. The BMD of lumbar spine and proximal femur was determined by dual-energy X-ray absorptiometry. Anteroposterior and lateral radiographs of the thoracic and lumbar spine were also obtained. The mean age of the two groups did not differ significantly. Mean time of transplantation was $25.4 \pm 21.1$ months (6 to 88 months). Except for the albumin levels, which were significantly higher, and magnesium levels, which were significantly lower in HT patients when compared to CHF patients, all other biochemical parameters and hormone levels were within the normal range and similar in the two groups. Both groups had lower BMD of the spine and proximal femur compared to young healthy adults. However, the mean BMD of HT patients was significantly lower than in CHF patients at all sites studied. Bone mass did not correlate with time after transplantation or cumulative dose of cyclosporine A. There was a negative correlation between BMD and the cumulative dose of prednisone. These data suggest that bone loss occurs in HT patients mainly due to the use of corticosteroids and that in $30 \%$ of the patients it can be present before transplantation. It seems that cyclosporine A may also play a role in this loss.
\end{abstract}

\section{Introduction}

Organ transplantation became an important field of medical practice after the advent and availability of the immunosuppressive drug cyclosporine A (1). Bone loss following transplantation has been recently reported (2-6); as a result, osteoporotic fractures can seriously compromise the quality of life of these patients. In contrast to transplantation of other organs such as kidney or liver, bone loss after heart transplantation (HT) is predominantly iatrogenic in view of the absence of any other previous metabolic disorder influencing bone metabolism in most patients (7). The impact of cyclosporine on bone is still controversial $(8,9)$. Cyclosporine A induces high-turnover osteopenia in the rat and may also contribute to bone loss after heart transplantation $(10,11)$. Prolonged immobilization can explain bone loss but the deleterious effect of glucocorticoid treatment on bone is also likely to be an important factor $(7,12)$.

It has been observed that heart transplant patients present the most rapid bone loss 
associated with fractures during the first year post-transplantation $(13,14)$. Sambrook et al. (15) have suggested that bone loss posttransplantation is due to a combination of accelerated turnover and hypogonadism. Thus, we investigated bone mass in heart transplant and in chronic heart failure (CHF) patients waiting for transplantation; furthermore, we evaluated the status and biochemical markers of bone resorption in these groups of patients.

\section{Patients and Methods}

HT and CHF patients waiting for transplantation and satisfying the eligibility criteria were consecutively recruited from the cardiology outpatient clinic at Escola Paulista de Medicina, UNIFESP, from February 1994 to December 1995 . Only ambulatory Caucasian males older than 18 years were included in the study. Only patients with more than six months of transplantation were included in the HT group. The etiology of the underlying heart disease included ischemic (34.4\%), idiopathic congestive (34.4\%), and Chagas' disease cardiomyopathy (24.6\%).

Exclusion criteria were gastrointestinal, liver, and kidney disease, kidney stones, diabetes, parathyroid or thyroid diseases, a vegetarian diet, present or past therapy, and treatment with medications known to affect bone metabolism (anticonvulsants, heparin, vitamin D metabolites, calcium supplements, aluminum-containing antacids). Sixty-six patients were screened and 61 met the eligibility criteria for this study, 30 for the HT group and 31 for the CHF group. All of them gave written informed consent to participate in the study, which was approved by the Ethics Committee of UNIFESP.

HT patients received initial and maintenance immunosuppression with cyclosporine, azathioprine, and prednisone. Steroids were administered as follows: methylprednisolone, 750-1000 $\mathrm{mg}$ for 3 days after surgery. Oral prednisone $\left(1.0 \mathrm{mg} \mathrm{kg}^{-1}\right.$ day $\left.^{-1}\right)$ was administered in divided doses until day 7 , reduced to $5-10 \mathrm{mg} /$ day for 6 weeks, and then withdrawn when possible. Ten patients (33\%) were taking no steroids at the time of the study. Cyclosporine therapy was started at the dose of $5 \mathrm{mg} / \mathrm{kg}$ orally on the fourth day of transplantation. Target levels were 150 to $200 \mathrm{ng} / \mathrm{ml}$ during the early phase of transplantation. Azathioprine was administered as a single dose of $4 \mathrm{mg} / \mathrm{kg}$ before surgery, and the maintenance dosage was 2 $\mathrm{mg} \mathrm{kg}^{-1}$ day $^{-1}$.

All patients were evaluated by the same observer and answered a questionnaire elaborated for this study.

Serum concentrations of total calcium, phosphorus, alkaline phosphatase, creatinine, albumin, and magnesium were measured by automated techniques (Kodak Ektachem 750 XRT). Testosterone was measured by immunoradiometric assay. Follicle-stimulating hormone (FSH) and luteinizing hormone (LH) were measured by immunofluorometric assay. Serum intact parathyroid hormone (PTH) concentration was measured by an immunoradiometric assay (16).

The urinary collagen crosslinks pyridinoline (Pyr) and deoxypyridinoline (D-Pyr) were determined by high-performance liquid chromatography and identified by spectrofluorimetry according to a modification of the method described by Black et al. (17) and Uebelhart et al. (18). The Pyr and D-Pyr values were determined by comparison with an external standard and corrected for creatinine excretion. The data are reported as pmol per $\mu \mathrm{mol}$ creatinine.

A standard set of anteroposterior and lateral radiographs of the thoracic and lumbar spine was obtained. Vertebral fracture was defined as the radiographic presence of a $20 \%$ or more anterior height reduction relative to the posterior height (19). The number of vertebral fractures was determined. The history of fractures at other sites was recorded, and X-rays were taken only when there was any doubt. All X-rays were 
evaluated by an examiner blind to the patient group.

Bone mineral density (BMD) of the lumbar spine and right proximal femur was measured by dual-energy X-ray absorptiometry utilizing a DPX Bone Densitometer (Lunar, Inc., Madison, WI). The in vivo coefficient of variation is $1.2 \%$ for the lumbar spine (L2-L4) and 2.0\% for the femoral neck. Measurements of BMD, reported as $\mathrm{g} / \mathrm{cm}^{2}$, were compared with those of young adults and age- and sex-matched normal subjects derived from the range indicated by the manufacturer. Standardized analyses were also used to compare individual BMD determinations to those of young adults (T-score) and age-matched (Z-score) controls. Only lumbar vertebrae radiographically shown to be intact were included in the bone density analysis. We also excluded patients with air artifacts on or around the major trochanter from analysis.

Statistical analysis was performed using the unpaired Student $t$-test and MannWhitney test. The Spearman rank correlation test was used to correlate time after transplantation, duration of CHF, cumulative doses of prednisone and cyclosporine-A with bone mass. Results are reported as means \pm SD. A P less than 0.05 was considered to be statistically significant.

\section{Results}

The clinical characteristics of the patients are shown in Table 1. The mean age of HT patients (48.6 \pm 10.8 years) was similar to that of CHF patients ( $43.5 \pm 10.5$ years), as also was height $(168.3 \pm 4.5$ vs $166.7 \pm 8.0$ $\mathrm{cm}$, respectively). The weight and body mass index of HT patients were significantly higher than those of CHF subjects $(76.2 \pm 10.7 v s$ $62.2 \pm 11.5 \mathrm{~kg}, \mathrm{P}<0.001 ; 26.8 \pm 3.3$ vs $22.3 \pm$ $3.6 \mathrm{~kg} / \mathrm{m}^{2}, \mathrm{P}<0.001$, respectively). Mean time after heart transplantation at the time of inclusion in the study was $25.4 \pm 21.1$ months (range: 6 to 88 months).

\section{Biochemical parameters}

Serum calcium, phosphorus, alkaline phosphatase, creatinine, testosterone, $\mathrm{PTH}$, FSH, LH, and urinary Pyr and D-Pyr excretion were normal for all patients and not significantly different between the two groups, although there was a trend to higher creatinine levels in the HT group. Albumin levels were significantly higher and magnesium levels were significantly lower in HT patients compared to CHF patients. The results of these biochemical determinations are summarized in Table 2.

Table 1 - Clinical characteristics of heart transplant (HT) recipients and chronic heart failure (CHF) patients.

Data are reported as means \pm SD. BMI, Body mass index. $* P<0.001$ versus HT (MannWhitney and Student t-test).

\begin{tabular}{lcc}
\hline & $\mathrm{HT}(\mathrm{N}=30)$ & $\mathrm{CHF}(\mathrm{N}=31)$ \\
\hline Age (years) & $48.6 \pm 10.8$ & $43.5 \pm 10.5$ \\
Weight $(\mathrm{kg})$ & $76.2 \pm 10.7$ & $62.2 \pm 11.5^{*}$ \\
Height $(\mathrm{cm})$ & $168.3 \pm 4.5$ & $166.7 \pm 8.0$ \\
$\mathrm{BMI}\left(\mathrm{kg} / \mathrm{m}^{2}\right)$ & $26.8 \pm 3.3$ & $22.3 \pm 3.6^{*}$ \\
Duration of CHF (months) & - & $18.0 \pm 21.1$ \\
Time after transplantation (months) & $25.4 \pm 21.1$ & - \\
Cumulative prednisone dosage (g) & $11.2 \pm 6.0$ & - \\
Cumulative cyclosporine A dosage (g) & $227.7 \pm 191.0$ & -
\end{tabular}

Table 2 - Biochemical parameters and hormonal determinations for heart transplant (HT) and chronic heart failure (CHF) patients.

Data are reported as means $\pm \mathrm{SD} . * \mathrm{P}<0.001$ versus $\mathrm{HT} . * * \mathrm{P}<0.008$ versus $\mathrm{HT}$ (MannWhitney and Student t-test).

\begin{tabular}{|c|c|c|c|c|c|}
\hline & HT & $\mathrm{N}$ & $\mathrm{CHF}$ & $\mathrm{N}$ & $\begin{array}{l}\text { Normal } \\
\text { values }\end{array}$ \\
\hline Calcium (mg/dl) & $9.6 \pm 0.6$ & 29 & $9.4 \pm 0.9$ & 17 & $8.5-10.5$ \\
\hline Phosphorus (mg/dl) & $3.3 \pm 0.5$ & 28 & $3.6 \pm 0.8$ & 12 & $2.5-4.5$ \\
\hline Alkaline phosphatase (U/l) & $115 \pm 40$ & 30 & $139 \pm 69$ & 29 & $50-180$ \\
\hline Magnesium (mg/dl) & $1.6 \pm 0.3$ & 30 & $2.1 \pm 0.3^{*}$ & 26 & $1.7-2.2$ \\
\hline Creatinine (mg/dl) & $1.3 \pm 0.4$ & 30 & $1.1 \pm 0.4$ & 29 & $0.6-1.4$ \\
\hline Albumin (g/dl) & $4.0 \pm 0.4$ & 30 & $3.6 \pm 0.7 * *$ & 28 & $3.2-5.6$ \\
\hline Total testosterone (ng/dl) & $447 \pm 146$ & 17 & $637 \pm 360$ & 12 & $350-900$ \\
\hline FSH (IU/I) & $2.0 \pm 1.4$ & 11 & $2.6 \pm 2.1$ & 6 & $1.0-12.0$ \\
\hline LH (IU/I) & $4.6 \pm 2.3$ & 21 & $4.5 \pm 4.7$ & 9 & $1.0-10.0$ \\
\hline Intact PTH (pg/ml) & $65.0 \pm 35.5$ & 23 & $54.3 \pm 68.2$ & 9 & $4-70$ \\
\hline 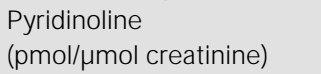 & $44.7 \pm 26.0$ & 19 & $43.4 \pm 19.8$ & 14 & $11-77$ \\
\hline $\begin{array}{l}\text { Deoxypyridinoline } \\
\text { (pmol/umol creatinine) }\end{array}$ & $4.4 \pm 2.1$ & 19 & $2.8 \pm 1.7$ & 14 & $0.6-6.3$ \\
\hline
\end{tabular}




\section{Bone densitometry}

The bone density determinations of the lumbar spine and proximal femur are shown in Table 3.

T-scores for the lumbar spine and proximal femur were below normal levels in HT patients and around -1.0 in CHF patients. The mean BMD of HT patients was significantly lower than in CHF patients at all sites. When the BMD of both groups was compared to that of age-matched controls, CHF patients could be considered normal since their Z-scores at all sites were between - 0.18 and -0.48 , while the Z-scores of HT patients remained below -1.0 at all sites.

Bone mass did not correlate with time after transplantation ( $\mathrm{rs}=-0.31$, NS in the lumbar spine; $\mathrm{rs}=-0.31$, NS in the femoral neck; rs $=-0.28$, NS in the trochanter) or cumulative dosage of cyclosporine $(\mathrm{rs}=$ -0.31 , NS for the lumbar spine; $r s=-0.24$, NS for the femoral neck; rs $=-0.20$, NS for the trochanter). In the CHF group, bone mass did not correlate with duration of congestive heart failure ( $\mathrm{rs}=-0.18$, NS for the lumbar spine; rs $=0.07$, NS for the femoral neck; rs $=0.01$, NS for the trochanter). There was a negative correlation between BMD at all sites and cumulative dose of prednisone $(r=$ $-0.53, \mathrm{P}<0.003$ for the lumbar spine; $\mathrm{r}=$ $-0.37, \mathrm{P}<0.05$ for the femoral neck; $\mathrm{r}=-0.36$, $\mathrm{P}<0.05$ for the trochanter). We did not observe significant differences between HT patients taking corticosteroids and patients who were not on corticotherapy at the time of the study.

\section{Vertebral fractures}

Vertebral fractures were observed in 15 $(50 \%)$ of HT patients and in four $(16 \%)$ of 25 radiographs of CHF patients examined. In 5 patients awaiting transplants, it was not possible to obtain radiographs. Lumbar BMD did not differ significantly between those with and those without vertebral fractures, although the average lumbar BMD and lumbar Z-score tended to be lower among HT patients with vertebral fractures. HT patients with vertebral fractures were significantly older than those without fractures. The T6 and $\mathrm{T} 7$ thoracic vertebrae were the most frequently fractured in HT patients $(\mathrm{G}=$ 25.47, $\mathrm{P}<0.05)$. No laboratory parameters, including PTH, Pyr, and D-Pyr, differed between patients with and without fractures. CHF patients with and without fractures presented similar results for all laboratory parameters analyzed.

\section{Discussion}

These data suggest that patients who underwent heart transplantation have an additional bone loss in the spine and proximal femur when compared to CHF patients. When compared to patients awaiting transplant,

Table 3 - Bone mineral density (BMD) of heart transplant (HT) and chronic heart failure (CHF) patients.

Data are reported as means $\pm \mathrm{SD}$. BMD, Bone mineral density. ${ }^{*} \mathrm{P}<0.05$ versus CHF patients. $* * \mathrm{P}<0.007$ versus CHF patients. $+\mathrm{P}<0.004$ versus $\mathrm{CHF}$ patients (Mann-Whitney test).

\begin{tabular}{|c|c|c|c|c|c|c|}
\hline & \multicolumn{2}{|c|}{ Lumbar spine } & \multicolumn{2}{|c|}{ Femoral neck } & \multicolumn{2}{|c|}{ Trochanter } \\
\hline & HT & $\mathrm{CHF}$ & HT & $\mathrm{CHF}$ & HT & $\mathrm{CHF}$ \\
\hline No. of patients & 29 & 29 & 30 & 31 & 29 & 26 \\
\hline BMD $\left(\mathrm{g} / \mathrm{cm}^{2}\right)$ & $1.04 \pm 0.14 *$ & $1.12 \pm 0.16$ & $0.86 \pm 0.14 *$ & $0.95 \pm 0.16$ & $0.75 \pm 0.11^{*}$ & $=0.82 \pm 0.12$ \\
\hline T Score & $-1.70 \pm 1.19 *$ & $-0.98 \pm 1.37$ & $-1.71 \pm 1.18^{*}$ & $-0.98 \pm 1.32$ & $-1.67 \pm 1.04 *$ & $-1.01 \pm 1.11$ \\
\hline ZScore & $-1.26 \pm 1.15^{* *}$ & $-0.29 \pm 1.23$ & $-1.08 \pm 0.97^{+}$ & $-0.18 \pm 1.20$ & $-1.41 \pm 0.93^{+}$ & $-0.48 \pm 1.12$ \\
\hline
\end{tabular}


the BMD of HT patients was $7.5 \%$ lower in the spine and $8.9 \%$ lower in the femoral neck and trochanter.

The pathogenic mechanisms leading to osteoporosis after heart transplantation are not well understood. Known or suspected risk factors for osteoporosis including negative calcium balance, physical inactivity, dietary calcium deficiency, exposure to tobacco and/or alcohol, and therapy with loop diuretics are often present. Lower testosterone levels could be another reason for osteopenia in HT patients receiving cyclosporine treatment (20). Osteopenia may be present prior to cardiac transplantation. Our data suggest that CHF patients have bone loss, since they have T-scores around -1.0. However, comparing them to age-matched controls, we found reduced bone mass only in $30 \%$ of patients, and their mean Z-score was around -0.3 . Shane et al. (21), studying 101 patients with severe CHF, observed osteopenia or osteoporosis in approximately half of the patients, and concluded that evidence of increased bone resorption was associated with abnormal concentrations of calciotropic hormones and with the severity of CHF.

Our study demonstrated that skeletal osteopenia is present in a significant proportion of patients submitted to heart transplantation. Other authors, using similar techniques to measure bone density, also found bone loss in the spine and proximal femur (14,22-24). In contrast, Lee et al. (25) reported bone loss only in the femoral neck in both transplanted and pre-transplanted patients, with no significant difference between them.

Fifty percent of patients who had undergone transplants showed radiological evidence of one or more compression fractures, compared to $16 \%$ of CHF patients who were awaiting transplantation. Mean vertebral bone density was not significantly different between the two groups. Although we found a negative correlation between BMD and cumulative doses of prednisone, we did not find that HT patients with fractures used higher doses of this drug or of cyclosporine than patients with no fractures. Of all other variables analyzed, only mean age of fractured patients was significantly higher. These results differ from those obtained by Muchmore et al. (5), who found that although there was much variation in the values of BMD that were obtained, almost all of their HT patients lost vertebral BMD after transplantation; however, none of their patients had vertebral compression fractures.

The basis for the increased proportion of transplanted patients with vertebral compression fractures compared to patients awaiting transplant is unclear. Except for the cumulative dose of corticosteroid, no other clinical parameters predicted BMD, including time since transplantation, cumulative dose of cyclosporine, or duration of congestive heart failure.

Some factors can be related to bone loss after cardiac transplantation. Sambrook et al. (15) suggested that bone loss after cardiac transplantation is related to hypogonadism due to the initial high doses of corticosteroids that these patients receive immediately after surgery. These authors observed decreased serum levels of testosterone immediately after surgery. In the present study, testosterone, LH, and FSH levels were not significantly different between groups. The difference between our results and those reported in Sambrook's study may have been due to the small number of patients in this study for whom it was possible to measure these hormones, since there was a trend to lower serum testosterone levels in HT patients (447 vs $637 \mathrm{mg} / \mathrm{dl})$.

All serum laboratory measurements were normal and not significantly different between the two groups, except for magnesium and albumin. Serum albumin levels were significantly higher in HT patients. This result was expected. Higher serum albumin levels in HT patients could reflect better 
ingestion of proteins and resolution of cardiac cachexia. On this basis, higher bone mass might be expected for HT patients, but this was not the case. On the other hand, higher serum albumin levels in HT patients might indicate an excessive ingestion of proteins, determining a negative balance of calcium and bone loss (26). We do not believe, however, that the ingested protein played a substantial role in the decreased bone density found in HT patients.

We found lower magnesium levels in HT patients compared to CHF patients. This was not expected, since we believed that CHF patients would also have low magnesium levels due to diuretic-induced renal loss. Cyclosporine use may justify the lower magnesium levels in HT patients due to the greater renal excretion that occurs with the use of this drug $(1,27)$.

Magnesium may affect bone resorption. Johannesson and Raisz (28) reported lower resorption in response to $\mathrm{PTH}$ and $1,25(\mathrm{OH})^{2} \mathrm{D} 3$ in magnesium-deficient bone. Hypomagnesemia was associated with lower PTH synthesis and secretion (29-31) and with altered target organ responsiveness to PTH action (30). Mg supplementation for 2 years significantly increased BMD in patients with osteoporosis associated with gluten-sensitive enteropathy (32).

Hypomagnesemia associated with low bone mass in HT patients has never been suggested before. Shane et al. (33) found normal magnesium levels in transplanted recipients. Other studies are needed to determine the importance of this factor in heart transplantation.

Pyr and D-Pyr were similar in both groups. These are well-known parameters of bone resorption. Other authors observed higher levels of bone resorption markers and decreases in serum testosterone and osteocalcin immediately after transplantation $(14,24)$. Sambrook et al. (15) even suggested that osteocalcin could be used as a predictive measurement of bone loss in these patients.
Although urinary crosslink excretion was not elevated, serum osteocalcin and bonespecific alkaline phosphatase were not measured, and these parameters might be helpful in order to determine whether or not cyclosporine or corticosteroid had any significant influence on bone turnover and the osteoporosis detected in patients submitted to heart transplantation.

Osteoporosis is a frequent complication of therapy with glucocorticoids, and it was not a surprise that the cumulative dose of prednisone was negatively correlated with BMD. Corticosteroid-induced osteoporosis is characterized by a disproportionate loss of trabecular bone relative to cortical bone (34), which explains extensive early observations showing that the spine is the major site of pathologic fracture and radiographic disease.

The action of cyclosporine on bone is controversial. It has been postulated to cause bone loss in transplant recipients (7). In vitro studies have demonstrated that cyclosporine decreases bone resorption (35-37), while in vivo experiments on rats have resulted in severe high-turnover osteopenia without any changes in ionized calcium, phosphate, or PTH levels (10-11,38).

The combined action of cyclosporine and prednisone on human bone has not been well established. When HT patients treated with this therapeutic scheme were compared to patients with immunologic diseases treated only with prednisone, osteocalcin levels were found to be significantly higher in patients who received both drugs (39). However, it is possible that cyclosporine decreases the inhibitory action of glucocorticoids on bone formation, leading to an accelerated bone formation state. In vivo experiments in rats have demonstrated that the combined use of glucocorticoids and cyclosporine minimized the adverse bone effects of either agent alone (40). We did not consider the cumulative dose of cyclosporine to predict BMD or incidence of vertebral fractures in our patients. 
It seems to us that cyclosporine interferes with the corticosteroid action on bone, changing the loss due to decreased bone formation characteristic of corticosteroid-induced osteoporosis to a high-turnover bone state, with high bone formation and resorption. Thus, the pathogenesis of osteoporosis in these patients is considerably different from that described for patients using only corticosteroids.

Prevention and treatment of bone loss in transplant recipients may be as important as the control of any other possible symptoms that may be observed in this population.

\section{References}

1. Kahan BD (1989). Cyclosporine. New England J ournal of Medicine, 321: 1725-1738.

2. Kelly PJ, Atkinson K, Ward RL, Sambrook PN, Biggs JC \& Eisman J A (1990). Reduced bone mineral density in men and women with allogeneic bone marrow transplantation. Transplantation, 50: 881883.

3. Julian BA, Laskow DA, Dubovsky J, Dubovsky EV, Curtis JJ \& Quarles D (1991). Rapid loss of vertebral mineral density after renal transplantation. New England J ournal of Medicine, 325: 544550.

4. Porayko MK, Wiesner RH, Hay J E, Krom RAF, Dickson ER, Beaver S \& Schwerman $L$ (1991). Bone disease in liver transplant recipients: incidence, timing, and risk factors. Transplantation Proceedings, 23: 1462-1465.

5. Muchmore J S, Cooper DKC, Ye Y, Schlegel VT \& Zuhdi N (1991). Loss of vertebral bone density in heart transplant patients. Transplantation Proceedings, 23: 1184-1185.

6. Meys E, Terreaux-Duvert F, Beaume-Six T, Dureau G \& Meunier PJ (1993). Bone loss after cardiac transplantation: effects of calcium, calcidiol and monofluorophosphatase. Osteoporosis International, 3: 322-329.

7. Katz IA \& Epstein S (1992). Perspectives: posttransplantation bone disease. J ournal of Bone and Mineral Research, 7: 123126.

8. Epstein S (1991). Cyclosporin A: friend or foe? Calcified Tissue International, 49: 232-234.

9. Epstein S (1996). Post-transplantation bone disease: the role of immunosuppressive agents and the skeleton. J ournal of Bone and Mineral Research, 11: 1-7.

10. Movsowitz C, Epstein S, Fallon M, Ismail $F \&$ Thomas S (1988). Cyclosporin-A in vivo produces severe osteopenia in the rat: effect of dose and duration of administration. Endocrinology, 123: 2571-2577.
11. Movsowitz C, Epstein S, Ismail F, Fallon $M \&$ Thomas S (1989). Cyclosporin-A in the oophorectomized rat: unexpected severe bone resorption. J ournal of Bone and Mineral Research, 4: 393-398.

12. Lukert BP \& Raisz LG (1990). Glucocorticoid-induced osteoporosis: pathogenesis and management. Annals of Internal Medicine, 112: 352-364.

13. Shane $E$, Rivas $M$, Staron RB, Silverberg SJ, Seibel MJ, Kuiper J, Mancini D, Addesso V, Michler RE \& Factor-Litvak P (1996). Fracture after cardiac transplantation: a prospective longitudinal study. J ournal of Clinical Endocrinology and Metabolism, 81: 1740-1746.

14. Shane E, Rivas M, McMahon DJ, Staron RB, Silverberg SJ , Seibel MJ , Mancini D, Michler RE, Aaronson K, Addesso V \& Lo SH (1997). Bone loss and turnover after cardiac transplantation. J ournal of Clinical Endocrinology and Metabolism, 82: 14971506.

15. Sambrook PN, Kelly PJ, Fontana D, Nguyen T, Keogh A, Macdonald P, Spratt P, Freund J \& Eisman J A (1994). Mechanisms of rapid bone loss following cardiac transplantation. Osteoporosis International, 4: 273-276.

16. Vieira J GH, Nishida SK, Kasamatsu TS, Amarante EC \& Kunii IS (1994). Development and clinical application of an immunofluorometric assay for intact parathyroid hormone. Brazilian J ournal of Medical and Biological Research, 27: 23792382.

17. Black D, Duncan A \& Robins SP (1988). Quantitative analysis of the pyridinium crosslinks of collagen in urine using ionpaired reversed-phase high-performance liquid chromatography. Annals of Biochemistry, 169: 197-203.

18. Uebelhart D, Gineyts E, Chapuy MC \& Delmas PC (1990). Urinary excretion of pyridinium crosslinks: a new marker of bone resorption in metabolic bone disease. Bone and M ineral, 8: 87-96.
19. Riggs BL, Seeman E, Hodgson SF, Taves DR \& O'Falloon WM (1982). Effect of fluoride/calcium regimen on vertebral fracture occurrence in postmenopausal osteoporosis. New England J ournal of Medicine, 306: 446-450.

20. Bowman AR, Sass DA, Dissanayake IR, Ma YF, Liang $\mathrm{H}$, Yuan Z, J ee WS \& Epstein $S$ (1997). The role of testosterone in cyclosporine-induced osteopenia. J ournal of Bone and Mineral Research, 12: 607-615.

21. Shane $E$, Mancini D, Aaronson K, Silverberg SJ , Seibel MJ , Addesso V \& McMahon DJ (1997). Bone mass, vitamin $D$ deficiency, and hyperparathyroidism in congestive heart failure. American J ournal of Medicine, 103: 197-207.

22. Rich GM, Mudge GH, Laffel GL \& LeBoff MS (1992). Cyclosporine A and prednisone-associated osteoporosis in heart transplant patients. J ournal of Heart and Lung Transplantation, 11: 950-958.

23. Rozenberg $S$, Oberlin F, Dorent R, Koeger AC, Frih L, Gandjbackch I \& Bourgeois P (1995). Study of bone mineral density after cardiac transplantation. Transplantation Proceedings, 27: 1692-1693.

24. Sambrook PN, Kelly PJ, Keogh AM, Macdonald $\mathrm{P}$, Spratt $\mathrm{P}$, Freund $\&$ Eisman J A (1994). Bone loss after heart transplantation: a prospective study. J ournal of Heart and Lung Transplantation, 13: 116121.

25. Lee $A H$, Mull RL, Keenan GF, Callegari PE, Dalinka MK, Eisen HJ , Mancini DM, DiSesa VJ \& Attie MF (1994). Osteoporosis and bone morbidity in cardiac transplant recipients. American J ournal of Medicine, 96: 35-41.

26. Orwoll ES (1992). The effects of dietary protein insufficiency and excess on skeletal health. Bone, 13: 343-350.

27. Millane TA, J ennison SH, Mann J M, Holt DW, McKenna WJ \& Camm AJ (1992). Myocardial magnesium depletion associated with prolonged hypomagnesemia: a longitudinal study in heart transplant re- 
cipients. J ournal of the American College of Cardiology, 20: 806-812.

28. J ohannesson AJ \& Raisz LG (1983). Effects of low medium magnesium concentration on bone resorption in response to parathyroid hormone and 1,25-dihydroxyvitamin D in organ culture. Endrocrinology, 113: 2294-2298.

29. J acob Al, Pennell P, Lambert PW \& Gavellas G (1981). Vitamin D metabolites and parathyroid hormone in hypomagnesemic hypocalcemia. Mineral and Electrolyte Metabolism, 6: 316-322.

30. Dirks J H (1983). The kidney and magnesium regulation. Kidney International, 23: 771-777.

31. Duran MJ , Borst GC, Osbume RC \& Eil C (1984). Concurrent renal hypomagnesemia and hypoparathyroidism with normal parathormone responsiveness. American J ournal of Medicine, 76: 151-154.

32. Rude RK \& Olerich M (1996). Magnesium deficiency: possible role in osteoporosis associated with gluten-sensitive enteropathy. Osteoporosis International, 6: 453-461.

33. Shane E, Rivas M, Silverberg SJ , Kim TS, Staron RB \& Bilezikian JP (1993). Osteoporosis after cardiac transplantation. American J ournal of Medicine, 94: 257264.

34. Hahn TJ , Boisseau VC \& Avioli LV (1974). Effect of chronic corticosteroid administration on diaphyseal and metaphyseal bone mass. J ournal of Clinical Endocrinology and Metabolism, 39: 274-282.

35. Stewart PJ , Green OC \& Stern PH (1986). Cyclosporin A inhibits calcemic hormoneinduced bone resorption in vitro. J ournal of Bone and Mineral Research, 1: 285291.

36. Klaushofer K, Hoffmann PJ, Stewart PJ , Czerwenka E, Koller K, Peterlik M \& Stern PH (1987). Cyclosporine A inhibits bone resorption in cultured neonatal mouse calvaria. J ournal of Pharmacology and Exper- imental Therapeutics, 243: 584-590.

37. Stewart PJ \& Stern PH (1989). Interaction of cyclosporine $A$ and calcitonin on bone resoption in vitro. Hormonal and Metabolic Research, 21: 194-197.

38. Schlosberg M, Movsowitz C, Epstein S, Ismail F, Fallon MD \& Thomas S (1989). The effect of cyclosporin A administration and its withdrawal on bone mineral metabolism in the rat. Endocrinology, 124: 2179-2184.

39. Kelly PJ, Sambrook PN \& Eisman JA (1989). Potential protection by cyclosporin against glucocorticoid effects on bone. Lancet, ii: 1388.

40. Movsowitz C, Schlosberg M, Epstein S, Ismail F, Fallon M \& Thomas S (1990). Combined treatment with cyclosporin A and cortisone acetate minimizes the adverse bone effects of either agent alone. J ournal of Orthopaedic Research, 8: 635641. 